\title{
STANDARDIZING THE DEFINITION OF A "PULSE" THUNDERSTORM
}

Paul W. Miller and Thomas L. Mote

The lexical evolution of "pulse thunderstorm" within meteorological texts is chronicled, revealing two common, yet incompatible, present-day uses. A standard definition is proposed.

"P ulse thunderstorm" is a widely recognized term within the meteorological lexicon. Though its applications vary, contemporary uses of "pulse" broadly reference a small, shortlived, and isolated updraft forming in a weakly sheared environment. Aside from pulse (and its sister term "pulse type"), the weather nomenclature also contains several other words to describe disorganized convection (see www.spc.noaa.gov /faq/\#4.4 for a description of "organized" versus "disorganized" thunderstorms). "Airmass," "ordinary," "garden variety," and "single cell" are all commonly used to indicate unicellular, nonsupercellular convection. Meanwhile, broadcast meteorologists frequently opt for the phrase "pop up" or "popcorn" thunderstorm to communicate this convective mode to their audiences.

AfFiliations: MiLleR AND MOTE-Department of Geography, The University of Georgia, Athens, Georgia CORRESPONDING AUTHOR: Paul W. Miller, paul.miller@uga.edu

The abstract for this article can be found in this issue, following the table of contents.

DOI:10.II75/BAMS-D-16-0064.I

A supplement to this article is available online (10.1175/BAMS-D-16-0064.2)

In final form 7 September 2016

()2017 American Meteorological Society
These storms are a staple feature of the summer climate across the central and eastern United States. Fueled by the diurnal instability, short-lived, isolated convection generally forms during the afternoon in hot, humid, summertime air masses. Typically lasting between $30 \mathrm{~min}$ and $1 \mathrm{~h}$, each cell consists of a three-stage life cycle (i.e., the cumulus, mature, and dissipating stages) first described by Byers and Braham (1949) during the Thunderstorm Project. These cloud formations are almost a daily feature of the southeastern U.S. sky during the warm season.

While most disorganized thunderstorms cause relatively little human inconvenience, the strongest cells can produce surface conditions exceeding severe weather warning criteria. Pulse thunderstorms are generally not tornado producers (relative to supercell thunderstorms), but their associated large hail and high wind threats can be particularly troublesome to diagnose. Consequently, meteorologists experience considerable difficulty in issuing accurate severe weather warnings for pulse thunderstorms. False alarm ratios (FARs) are larger and probabilities of detection (PODs) are smaller for warnings issued on pulse thunderstorms than for other storm modes (Guillot et al. 2008). However, perhaps their greatest impact on human activity occurs in the absence of severe weather. Even when their outflow winds remain below severe criteria, the dangerous shear 
conditions created by pulse-storm microbursts can lead to aviation tragedy (e.g., NTSB 1986). Further, more individuals are killed by lightning strikes from pulse storms than any other convective mode (Ashley and Gilson 2009).

Though many meteorologists are familiar with the term "pulse," its applications in the meteorological literature suggest it has multiple connotations within the field. "Pulse" was originally intended to reference a briefly severe member of a multicell thunderstorm complex, typically forming in a weakly sheared environment (L. Lemon 2015, personal communication). However, in recent decades the application of this term has broadened to also describe nonsevere storms while simultaneously narrowing to exclude multicellular structures. As the meteorological community focuses more attention on clearly and effectively communicating weather hazards to the public, the array of terminology used to describe disorganized convection is a self-inflicted handicap. This is a timely discussion given that general circulation models suggest that unstable, weakly sheared atmospheres will become increasingly frequent in future climate scenarios (Diffenbaugh et al. 2013; Gensini and Mote 2015), and references to pulse storms may become more common as a result. To facilitate new research into these difficult-to-forecast storms, as well as to effectively communicate their potential hazards, a standard nomenclature for disorganized convection is needed.

The purpose of this paper is to propose a common definition for a pulse thunderstorm. However, in doing so the nomenclature of all disorganized convection must also be addressed. In subsequent sections, this paper 1) summarizes the historical development of the term "pulse" and its use within academic and educational contexts, 2) performs a content analysis of Storm Prediction Center (SPC) text products to infer "pulse" applications in an operational setting, and 3) describes the deficiencies with the current terminology. We conclude by suggesting a consolidated nomenclature for disorganized convection, including a standard application for "pulse thunderstorm."

\section{A BRIEF HISTORY OF THE TERM “PULSE.”}

"Pulse" was first coined as a thunderstorm mode descriptor by Wilk et al. (1979). ${ }^{1}$ This document, created for a Federal Aviation Administration (FAA) training program, was prepared by researchers at the National Severe Storms Laboratory (NSSL). According to one

${ }^{1}$ Wilk et al. (1979) is no longer accessible, but readers seeking more information can reference Burgess and Lemon (1990) for a similar definition. of the coauthors, "pulse" was intended to describe "a multicellular storm that is largely non-severe. However, occasionally one cell within the multicellular complex will briefly become severe." The authors selected the word "pulse" to reference a "local surge of the updraft portion of the cell" that was structured as a discrete bubble rather than a current (L. Lemon 2015, personal communication). The pulse was seen as the mechanism responsible for the subsequent severe weather.

This original meaning was essentially preserved in both educational and research texts for the first 20 years of the term's existence, as indicated by a chronology of such resources in Table ES1 in the online supplement to this article (http://dx.doi.org//0.1175 /BAMS-D-16-0064.2). However, the application of the term broadened following the new millennium. Cerniglia and Snyder (2002) are the first to make an explicit reference to "non-severe pulse storms," indicating that all cases of short-lived, isolated convection may be termed "pulse." In the ensuing decades, this interpretation has become increasingly frequent. Nine of the 18 textbooks, web tutorials, and research papers in Table ES1 produced after 2000 appear to either apply "pulse" as a synonym for all isolated ordinary-cell convection or abstain from including a severe weather criterion in their definition. As the meaning of "pulse" expanded to include nonsevere thunderstorms, a new variation gained traction within the severe weather lexicon: "pulse severe" (e.g., Cerniglia and Snyder 2002; Miller and Petrolito 2008). The need for an explicitly severe variation of the term further illustrates the evolved meaning of "pulse" proper. "Pulse" also appears in many other journal articles and Internet resources, but the reference is too brief to confidently infer the authors' concept of this storm mode.

The definitions provided by the current National Weather Service (NWS) and American Meteorological Society (AMS) glossaries (Table ES2 in the online supplement) presumably offer credible standards for disorganized convection terminology. Though the NWS glossary (NWS 2016) defines more of the current lexicon than the AMS Glossary of Meteorology (AMS 2016), its definitions demonstrate the same evolution evident in research texts. Separate entries are given to "pulse" and "pulse severe," and these definitions are not similar. The NWS "pulse severe" definition requires that the storm be a single cell, but "pulse" does not. According to the NWS glossary, a convective line segment or a supercell could qualify as a pulse storm if the period of severe weather were sufficiently brief. Although the NWS definition is clear that severe weather is to be associated with 
this storm mode, the requirement that a pulse severe storm adhere to single-cell expectations is inconsistent with Wilk et al. (1979). Despite the AMS's formal procedure for fielding and reviewing user-suggested definitions, the online open-access Glossary of Meteorology largely reflects definitions published in the original (Huschke 1959) and revised (Glickman 2000) hardcopy editions. Consequently, neither "pulse" nor any of its variant forms are defined; only the definition for "ordinary cell" is explicitly provided. ${ }^{2}$ Entries for "airmass thunderstorm" and "convective cell" redirect to "airmass shower" and "cell," respectively, creating confusion over whether the redirected term is synonymous with the first.

THE USE OF “PULSE” IN SPC TEXT PRODUCTS. This section surveys hundreds of SPC convective outlooks (COs) and mesoscale discussions (MDs) (SPC 2015) to gauge operational applications of "pulse" in addition to its research and educational uses described above. While fewer than 30 research articles and textbooks were identified that use "pulse" with enough detail to discern the authors' concept of the storm mode (Table ES1), operational products provide hundreds of accessible examples.

Data and methods. A content analysis (Krippendorff 2012) was performed using the publicly available web archive of SPC COs (www.spc.noaa.gov/products loutlook/) and MDs (www.spc.noaa.gov/products $/ \mathrm{md} /$ ) issued between 2003, the first year that the modern-format archive is available, and 2014. Any CO or MD that contained the term "pulse" was considered "pulse referencing" and became a candidate for the content analysis. The 12-yr archive yielded a pulse-referencing database of 997 COs and 458 MDs.

Put simply, content analysis is the quantitative analysis of qualitative data, a technique that has been previously applied to the atmospheric sciences (Harrison 1982; Stewart et al. 2016). The analysis was conducted in two stages. The first stage seeks to establish the credibility of "pulse" references in SPC operational products as a relevant commentary on storm mode through a word frequency analysis. Though less detailed than MDs, the larger sample of COs can be used to track instances of "pulse" through time and compare the temporal trends against traditional expectations.

The second stage of the analysis leverages the descriptive format of MDs to identify the vocabulary

\footnotetext{
${ }^{2}$ We intend to submit new definitions for the disorganized convection terminology discussed herein following the appearance of this article in printed form.
}

commonly used by forecasters in conjunction with "pulse." With single words serving as the unit of analysis, an inductive dictionary of pulse-related terms was developed following the five-step process recommended by Short et al. (2009) to optimize content validity. All words within the body of pulsereferencing MDs were considered candidates for the dictionary. This inductive technique differs from a deductive approach by forming the dictionary from observed recurring words rather than conceptually associated words that theoretically should recur.

The five-step process used in stage two is as follows. 1) Computer-aided text analysis software (McKenny et al. 2012) searched the archive of pulse-referencing MDs for recurring words. 2) The NWS glossary entry ${ }^{3}$ for "pulse severe thunderstorm" was selected as the working definition. 3) Two doctoral students identified a subset of terms from the list developed in step 1 associated with the definition selected in step 2. Each rater independently reviewed the entire set of recurring words. 4) The interrater reliability score (Holsti 1969), a value between 0 and 1 with higher scores indicating stronger rater agreement, was calculated to be 0.76 , with an alternative measure, Krippendorff's $\alpha$ statistic (Krippendorff 2012), yielding 0.72.5) The raters compared their results, conferred over the discrepancies in their subsets, and mutually agreed upon the final 62-term dictionary that is shown in Table 1 .

This inductive technique is meant to provide a broad overview of pulse-related word choice patterns and will only partially consider word context through a collocation (recurring expressions of two or more words) analysis using the Natural Language Toolkit (Bird et al. 2009). Thirty-one different forecasters and 86 different coauthor combinations drafted the 458 pulse-referencing MDs.

Results. The results of the first stage, shown in Fig. 1, confirm that the operational usage of "pulse" in SPC COs adheres to the undisputed expectations of the term. Eighty-eight percent of "pulse" references appear between May and August (Fig. 1a) with usage also peaking in the late afternoon/early evening (1630 and 2000 UTC) on the day of concern (Fig. 1b). Figure 1c provides additional context by comparing the percent change in storm mode references as the outlook approaches the period of concern. Instances of "pulse" increase rapidly into day 1 with a $29.6 \%$ increase between the 1300 and 1630 UTC updates,

\footnotetext{
${ }^{3}$ Because the NWS definition for "pulse severe thunderstorm" references a "single-cell thunderstorm," the raters were instructed to select terms related to either definition.
} 


\begin{tabular}{|c|c|c|c|}
\hline \multicolumn{4}{|c|}{$\begin{array}{l}\text { TABLE I. Dictionary of } 62 \text { inductively identified } \\
\text { words frequently used by SPC forecasters in asso- } \\
\text { ciation with "pulse." The fractions of pulse-refer- } \\
\text { encing MDs containing each term are shown. }\end{array}$} \\
\hline Term & Fraction & Term & Fraction \\
\hline \begin{tabular}{|l|} 
Storms \\
\end{tabular} & 0.729 & \multirow{2}{*}{$\begin{array}{l}\text { TSTM } \\
\text { (thunderstorm) }\end{array}$} & \multirow{2}{*}{0.188} \\
\hline \begin{tabular}{|l|} 
Wind \\
\end{tabular} & 0.664 & & \\
\hline \begin{tabular}{|l|} 
Severe \\
\end{tabular} & 0.662 & Marginal & 0.183 \\
\hline Weak & 0.657 & Ascent & 0.181 \\
\hline \begin{tabular}{|l|} 
Shear \\
\end{tabular} & 0.651 & \multirow{2}{*}{$\begin{array}{l}\text { DMGG } \\
\text { (damaging) }\end{array}$} & \multirow{2}{*}{0.179} \\
\hline Hail & 0.638 & & \\
\hline \begin{tabular}{|l|} 
Isolated \\
\end{tabular} & 0.592 & Moisture & 0.172 \\
\hline Afternoon & 0.572 & Locally & 0.164 \\
\hline Strong & 0.537 & Weather & 0.153 \\
\hline Boundary & 0.507 & Clusters & 0.146 \\
\hline Lapse & 0.441 & Boundaries & 0.140 \\
\hline Gusts & 0.428 & Heavy & 0.138 \\
\hline Winds & 0.410 & Cells & 0.135 \\
\hline Instability & 0.393 & Intensity & 0.118 \\
\hline Convection & 0.382 & Brief & 0.114 \\
\hline Damaging & 0.360 & Rainfall & 0.107 \\
\hline Unstable & 0.360 & \multirow{2}{*}{$\begin{array}{l}\text { ISOLD } \\
\text { (isolated) }\end{array}$} & \multirow{2}{*}{0.103} \\
\hline Convective & 0.338 & & \\
\hline Heating & 0.334 & Intense & 0.094 \\
\hline Outflow & 0.317 & Stationary & 0.087 \\
\hline Storm & 0.308 & Small & 0.085 \\
\hline \begin{tabular}{|l|} 
TSTMs \\
(thunderstorms) \\
\end{tabular} & 0.299 & Downburst & 0.083 \\
\hline \begin{tabular}{|l|} 
Coverage \\
\end{tabular} & 0.297 & Damage & 0.081 \\
\hline Stronger & 0.295 & Gusty & 0.076 \\
\hline Evening & 0.277 & Numerous & 0.072 \\
\hline Thunderstorms & 0.245 & Cloud & 0.070 \\
\hline Marginally & 0.234 & Sporadic & 0.055 \\
\hline Airmass & 0.214 & Rain & 0.050 \\
\hline Thunderstorm & 0.210 & \multirow{2}{*}{$\begin{array}{l}\text { AFTN } \\
\text { (afternoon) }\end{array}$} & \multirow{2}{*}{0.033} \\
\hline Dewpoints & 0.207 & & \\
\hline Convergence & 0.205 & Updraft & 0.033 \\
\hline SVR (severe) & 0.205 & STG (strong) & 0.017 \\
\hline Organization & 0.190 & $\begin{array}{l}\begin{array}{l}\text { DEWPTS } \\
\text { (dewpoints) }\end{array} \\
\end{array}$ & 0.007 \\
\hline
\end{tabular}

roughly coincident with the onset of peak daytime heating. "Pulse" references then plummet dramatically following the loss of solar radiation. By comparison, references to "supercell" show less variation between each CO update period.

The second stage of the content analysis, performed on SPC MDs, yielded a 62-member pulse-term dictionary (Table 1) with the most frequently used dictionary words shown in Fig. 2. Three of the six dictionary words appearing in at least $60 \%$ of pulsereferencing MDs express well-acknowledged components of pulse thunderstorm descriptions ("storms," "weak," "shear"). Meanwhile, the other three terms ("severe," "wind," "hail") are closely tied to the NWS severe weather warning criteria. Table 2 explores the context of these words by identifying any recurring neighboring terms, and sheds greater light on how SPC forecasters often apply pulse-related terminology in their text. Many of the rater-identified terms in Table 1 are also quantitatively identified as members of these recurring phrases. Again, the association with weak vertical wind shear, large instability, and severe weather is clear. The collocations also indicate that the isolated severe threat posed by pulse thunderstorms, though worthy of an MD issuance, frequently fails to satisfy weather watch criteria.

We acknowledge that because the purpose of SPC MDs is to communicate severe weather potential, frequent severe weather language is expected. However, when referencing potentially severe storms in weakly sheared environments, "pulse" is the overwhelming word of choice in SPC MDs. Table 3 shows that "pulse" references account for $58.6 \%$ of the disorganized convection terminology. If variant forms (i.e., pulse type) are included, then the proportion rises to $97.5 \%$.

Although Table 1 was developed by examining pulse-referencing MDs, these words may simply be generic to all convection. If the terms in Table 1 are generic descriptors of all thunderstorms, then they would be expected to occur equally frequently across all convective MDs. If they are not generic descriptors, then they would be expected to occur less frequently in non-pulse-referencing MDs. Figure 3 supports the latter scenario by calculating the number of times a term in Table 1 appeared in an MD's text and stratifying the results by storm mode. Indeed, the mean score for pulse-referencing MDs (24.0) significantly exceeds that for supercell-referencing MDs (17.5; Student's $t$ test yields $p<0.001$ ). This suggests that supercell-referencing MDs are characterized by a different set of vocabulary than the pulse-related terms identified by the raters, and by extension, that Table 1 does not contain common language for all thunderstorms. However, the mean score for multicell-referencing MDs is statistically indistinguishable from pulse-referencing MDs (Fig. 3). The 62 pulserelated words in Table 1 are used equally frequently in MDs referencing multicell storms.

Combining the results from Figs. 2 and 3 and Table 3, the language contained in SPC pulse-referencing MDs 
resembles the traditional Wilk et al. (1979) description more than the nonsevere, singlecelled, contemporary application. The frequent inclusion of severe-weather-related language and the equal representation of pulse-related terms in multicell-referencing MDs supports a severe, multicellular nature to pulse thunderstorms. Because MDs are only a sample of the operational language, this result cannot be generalized across the whole operational community. Nevertheless, this analysis provides valuable insight into how the SPC's broad professional and lay-person readership (SPC 2015) is exposed to applications of "pulse."

\section{THE MOTIVATION FOR} STANDARDIZATION.

The inconsistent and variable terminology for disorganized convection may seem inconsequential on the surface, but it poses a real problem for effective communication. This section enumerates four major shortcomings of the current terminology that motivate the proposed standardization in the concluding section.

Redundancy. If the common phrase "pulse severe" is read with the Wilk et al. (1979) definition in mind, then the use of "severe" is redundant. More specifically, it is a form of linguistic error called pleonasm. Lehmann (2005) suggests that authors may sometimes choose to include redundant information in order to underscore a particular aspect of a word's meaning. In other situations, the inclusion of repeated information may be due to uncertainty about whether the predicate term already contains that information. For instance, an author might choose the phrase "pulse severe storm" to emphasize that a pulse storm is severe.
A
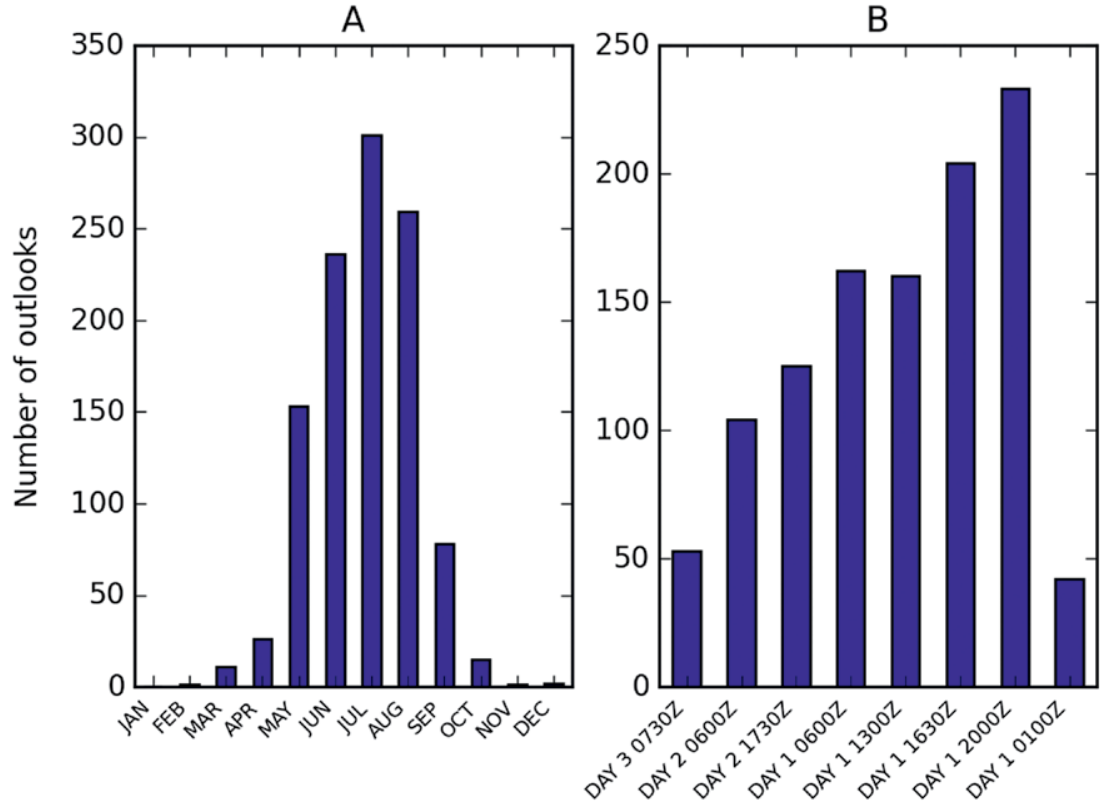

C

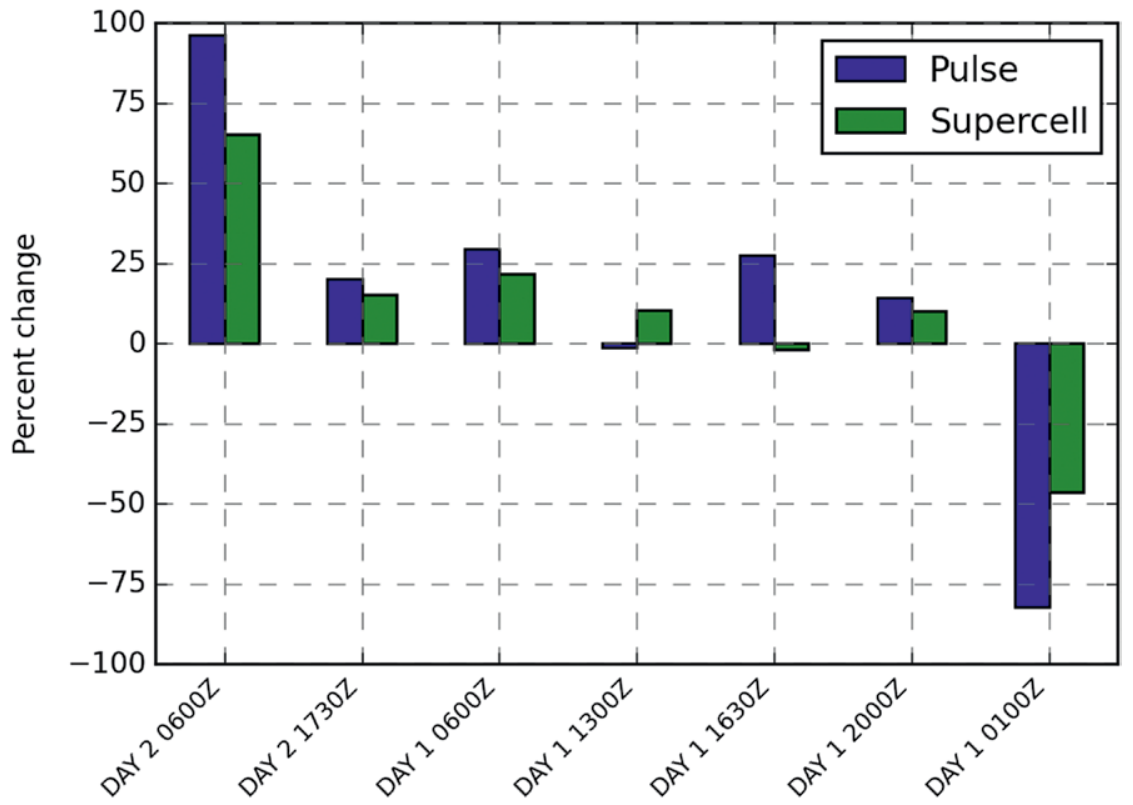

Fig. I. Distribution of "pulse" appearances in SPC COs (a) by month and (b) by outlook issuance. (c) Percent change in the number of references to "supercell" and "pulse" compared to the immediately preceding outlook period. There is a sharp increase in "pulse" uses during the day I 1630 UTC outlook accompanied by an $\mathbf{8 0} \%$ decrease following the loss of diurnal heating.
Alternatively, confused by the discrepancies in pulse thunderstorm definitions, the author might be unsure what the term actually means. The accompanying adjective "severe" is then intended to clarify elements of "pulse" that may be in doubt. Pleonasm, as with all redundancy, weakens the language that contains it (Grice 1975). "Pulse severe," though unambiguous in its association with severe weather, creates ambiguity 


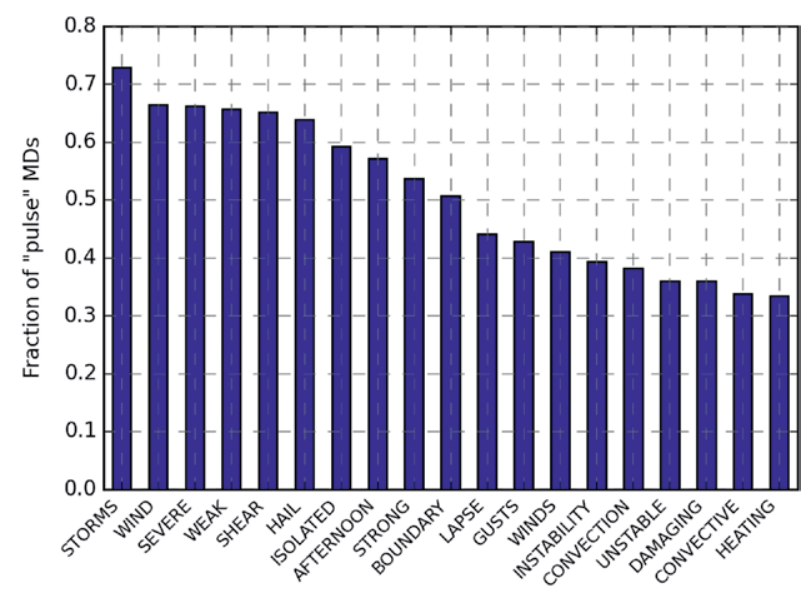

FIG. 2. Fraction of pulse-referencing MDs containing the terms in Table I. Only terms appearing in at least one-third of pulse-referencing MDs are compared.

by casting uncertainty on whether "pulse" alone implies severity. For comparison, pleonasm is less common for storm modes with a well-established, objective criterion. Few supercell-referencing MDs contain "mesocyclone" (0.7\%), "rotating" $(4.2 \%)$, or "rotation" (6.7\%), the defining element of a supercell thunderstorm. Until the pulse thunderstorm's definition is standardized, redundant phrasing will continue to confuse readers.

The pulse thunderstorm as a severe single cell. As the meaning of "pulse" has evolved, some sources now reference a pulse thunderstorm as a single-cell thunderstorm that produces severe weather (e.g., Bluestein 2013; NWS 2016). However, despite its ubiquity across the meteorological literature, there is relatively little precedent for a true single-cell thunderstorm. Though successfully simulated within a three-dimensional numerical cloud model by Weisman and Klemp (1982), a legitimate one-celled thunderstorm has proved elusive in field campaigns. Horace Byers, project director for the famed Thunderstorm Project, summarizes his field observations by saying, "While every storm must be one-celled at the beginning, the simple unicellular type was found to be rare because its period as a solitary cell lasts only a few minutes after it has reached rainy, thundery conditions. Thus, the textbook diagram of a thunderstorm, always unicellular, is misleading" (Byers 1949). Byers's conclusion was informed by 1,363 aircraft penetrations of 179 thunderstorms in two different regions at five vertical levels yielding 4,218 $\mathrm{min}$ (2.93 days) of flight recordings. Even the "most complete study of a single airmass storm since Byers and Braham" (Kingsmill and Wakimoto 1991) consisted of two small updrafts (Wakimoto and Bringi 1988). The concept of a single-cell thunderstorm, while valuable as a conceptual model, is disconnected from thorough field observations. If true single-cell thunderstorms occur so rarely, how can a pulse thunderstorm be a severe single cell?

A congested vocabulary. As mentioned previously, the meteorological lexicon contains a wealth of terms referring to short-lived, isolated, summertime thunderstorms. The modifiers "airmass," "ordinary," "single cell," "pop up," "popcorn,” "garden variety," "pulse," and "pulse type" are each commonly employed by meteorologists. Summing all these words yields a total of eight terms describing the same basic concept. At best, the "pulse" family references a severe subset of airmass/ordinary/single-cell/pop-up/popcorn/ garden-variety thunderstorms. Otherwise, all eight words essentially share the same meaning.

The congested vocabulary of disorganized convection is a significant barrier to research and public communication. If these terms are truly synonyms, then they should be consolidated for more effective communication. If they represent truly distinct phenomena, then they need to be clearly defined as such. In Eloquent Science: A Practical Guide to Becoming a Better Writer, Speaker, and Atmospheric Scientist, David

\begin{tabular}{|c|c|c|}
\hline Top 25 & jigrams & Top 3 trigrams \\
\hline Air mass & Damaging gusts & Steep lapse rates \\
\hline Steep lapse & Watch anticipated & $\begin{array}{c}\text { Weather watch } \\
\text { not }\end{array}$ \\
\hline Lapse rates & Weather not & \multirow{10}{*}{$\begin{array}{c}\text { Damaging wind } \\
\text { gusts }\end{array}$} \\
\hline Next hours & Watch not & \\
\hline Steep rates & Wind gusts & \\
\hline Not anticipated & Damaging winds & \\
\hline $\operatorname{MLCAPE}\left(\mathrm{J} \mathrm{kg}^{-1}\right)$ & Boundary layer & \\
\hline Deep layer & Marginally severe & \\
\hline Low level & Weak shear & \\
\hline Values $\left(\mathrm{J} \mathrm{kg}^{-1}\right)$ & Severe threat & \\
\hline Weather watch & Severe hail & \\
\hline $\begin{array}{c}\text { Outflow boundary } \\
\text { Large hail }\end{array}$ & Strong winds & \\
\hline
\end{tabular}


TABle 3. Counts of terms used to describe disorganized convection as they appear in SPC MDs between 2003 and 2014.

Term Count

\begin{tabular}{|lr|}
\hline Airmass & 7 \\
\hline Garden variety & 0 \\
\hline Ordinary & 0 \\
\hline Pop up & 0 \\
\hline Popcorn & 0 \\
\hline Pulse multicell & 29 \\
\hline Pulse & 323 \\
\hline Pulse severe & 31 \\
\hline Pulse-like & 28 \\
\hline Pulse type & 109 \\
\hline Pulse-type severe & 17 \\
\hline Single cell & 7 \\
\hline
\end{tabular}

Schultz writes on the subject of redundant jargon: "Sometimes multiple terms have arisen to describe the same thing...Part of good scholarship is not to create any more unnecessary terms, but to identify and clarify any discrepancies or confusion with existing terms. If multiple terms exist, consistency is key to communicating with your audience...Even terms we think we may be familiar with, we may misuse" (Schultz 2013, p. 91).

Inconsistent technical identification. Perhaps in response to the ambiguities stated above, researchers seeking to identify pulse thunderstorms employ widely varying criteria. Environmental thermodynamic and/or kinematic parameters, radar reflectivity factor, areal extent, temporal longevity, proximity to other convection, and (possibly) severe weather reports are often considered in their identification. Simultaneously, dynamical features, such as a radar-indicated mesocyclone, may be used to exclude a storm from being categorized as "pulse." Though the variables included in the classification process may be similar, the combination of variables and the choices of thresholds regularly differ. Several other attempts to identify pulse convection essentially treat the category as a "catchall" for storms failing to fit any other category (e.g., Cerniglia and Snyder 2002; Guillot et al. 2008; Ashley and Gilson 2009). While identification techniques are expected to differ between analyses, the variable categorization schemes can capture storms much different than the one envisioned by Wilk et al. (1979). Further, the variety of identification strategies inhibits reproducibility and comparisons of pulsestorm-related studies.

CONCLUSIONS. The revision of storm mode definitions is ongoing in other areas of mesoscale meteorology. Corfidi et al. (2016) have sought to initiate a similar conversation regarding the formal definition of a derecho. As the authors explain, "While questions of this sort may be dismissed as academic, they are not considering that meteorological terms increasingly are becoming part of the everyday lexicon, and that the use of concise, readily understood vocabulary is essential in communicating information to the general public." This same rationale is equally, if not more, applicable to pulse thunderstorms given their frequency during the summer.

Although an objective dynamical criterion (similar to that for a supercell) is most desirable, the paucity of pulse thunderstorm research precludes the suggestion of an appropriate feature at this time. Candidates for requisite dynamical signatures include radar-sensed divergence at the cloud top and base (Burgess and Lemon 1990) or the constriction feature described by Kingsmill and Wakimoto (1991). However, in the interim, the meteorological community would benefit by conceptually standardizing the definition of "pulse" and deciding what, if anything, differentiates it from other disorganized convection. With this goal in mind, a restructuring of the disorganized convection nomenclature is suggested below.

1) The basic conceptual model for a convective cell as outlined by Byers and Braham (1949) and simulated by Weisman and Klemp (1982) should be retained, but only for educational purposes. Often called a "single cell" thunderstorm, this term is misleading given the frequent multicellular nature of disorganized convection (Byers 1949). This idealized thunderstorm could instead be called a "Byers-Braham cell," a name introduced by Doswell (1985, p. 48), and the use of "single cell" thunderstorm should be avoided.

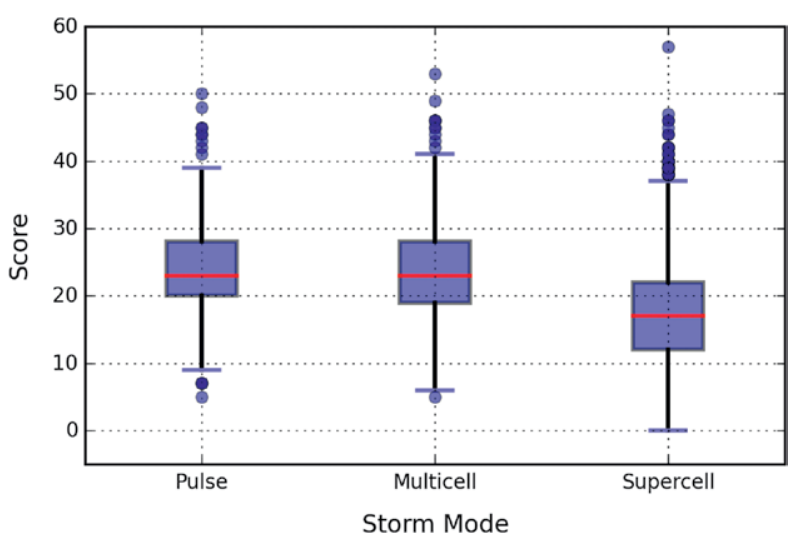

Fig. 3. Boxplots of Table I word scores for pulse-, multicell-, and supercell-referencing MDs. Median scores are indicated by red lines, and the shaded blue boxes demarcate the middle $\mathbf{5 0 \%}$ of the scores (i.e., the interquartile range). Outliers are depicted by blue circles placed beneath (above) the 25th (75th) percentile minus (plus) the interquartile range. 
2) When referring to the operational equivalent of the Byers-Braham cell, it should be acknowledged that nearly all disorganized convection is at least weakly multicellular. At risk of further congesting the lexicon, our initial thought was to retain "airmass thunderstorm" for this purpose because it is the only current option that communicates any information about the storm environment. However, a dialogue between the authors, reviewers, and editor concluded that by ignoring the role of mesoscale boundaries in convection initiation this term is also undesirable. We therefore recommend an essentially new, yet not unprecedented, alternative, which was also suggested during the review process: "weakly forced thunderstorm" (Rose et al. 2008; Bentley et al. 2012). Environments favorable for this storm mode are characterized by the instability and moisture necessary for convection. However, a synoptic lifting mechanism and its attendant shear regime are absent, imposing temporal and spatial limitations on any convection. Within the synoptically homogeneous air mass, weakly forced thunderstorm formation is routinely aided by both strong and subtle mesoscale variations in air temperature, moisture, and wind direction. Thus, weakly forced thunderstorms should be understood to reference synoptically weakly forced thunderstorms.

3) The subset of severe-weather-producing weakly forced thunderstorms could simply be called "severe weakly forced thunderstorms" without relying on any additional terminology. Such language perhaps even more directly communicates the anticipated hazards than does the term "pulse thunderstorm." However, given the predominance of "pulse" in the meteorological lexicon, standardizing future applications of "pulse" to reference severeweather-producing weakly forced thunderstorms is more practical than eliminating use of the word altogether. This proposed definition has a historical precedent stemming from Wilk et al. (1979) and a contemporary precedent in the SPC MDs. Because storm severity is included by this definition, pulse storms should not be described as severe.

As the meteorological lexicon expands and matures, it is only prudent to critically reevaluate our own vocabulary with the goal of optimizing clear and consistent communication. The abundance of terminology referencing brief, summertime convection impedes the clear, effective dissemination of severe weather hazards, and retards scientific research directed at these storms. This paper offers a prototype for future reevaluations of meteorological language while serving as an immediate call to thin and standardize the congested vocabulary of disorganized convection.

ACKNOWLEDGMENTS. The authors thank Dr. Alan Stewart for his helpful comments on an earlier draft of this essay. Exchanges between the authors, reviewers, and editor also greatly improved this essay as well as the quality of its recommendations.

\section{REFERENCES}

AMS, 2016: Glossary of Meteorology. [Available online at http://glossary.ametsoc.org/.]

Ashley, W. S., and C. W. Gilson, 2009: A reassessment of U.S. lightning mortality. Bull. Amer. Meteor. Soc., 90, 1501-1518, doi:10.1175/2009BAMS2765.1.

Bentley, M. L., J. A. Stallins, and W. S. Ashley, 2012: Synoptic environments favourable for urban convection in Atlanta, Georgia. Int. J. Climatol., 32, 1287-1294, doi:10.1002/joc.2344.

Bird, S., E. Loper, and E. Klein, 2009: Natural Language Processing with Python. O'Reilly Media, $604 \mathrm{pp}$.

Bluestein, H. B., 2013: Severe Convective Storms and Tornadoes: Observations and Dynamics. Springer, $456 \mathrm{pp}$.

Burgess, D. W., and L. R. Lemon, 1990: Severe thunderstorm detection by radar. Radar in Meteorology, D. Atlas, Ed., Amer. Meteor. Soc., 619-647.

Byers, H. R., 1949: Structure and dynamics of the thunderstorm. Science, 110, 291-294, doi:10.1126/ science.110.2856.291.

— port of the Thunderstorm Project. U.S. Government Printing Office, $287 \mathrm{pp}$.

Cerniglia, C. S., and W. R. Snyder, 2002: Development of warning criteria for severe pulse thunderstorms in the northeastern United States using the WSR88D. National Weather Service Eastern Region Tech. Attachment 2002-03, 14 pp. [Available online at http://docs.lib.noaa.gov/noaa_documents/NWS /NWS_ER/Eastern_Region_Tech_Attachment /TA_2002-03.pdf.]

Corfidi, S. F., M. C. Coniglio, A. E. Cohen, and C. M. Mead, 2016: A proposed revision to the definition of "derecho." Bull. Amer. Meteor. Soc., 97, 935-949, doi:10.1175/BAMS-D-14-00254.1.

Cover, T. M., and J. A. Thomas, 1991: Information theory and statistics. Elements of Information Theory, 1 ed., T. M. Cover and J. A. Thomas, Eds., John Wiley and Sons, 279-335.

Diffenbaugh, N. S., M. Scherer, and R. J. Trapp, 2013: Robust increases in severe thunderstorm environments in response to greenhouse forcing. Proc. Natl. 
Acad. Sci. USA, 110, $16361-16366$, doi:10.1073/ pnas. 1307758110.

Doswell, C. A., III, 1985: The operational meteorology of convective weather. Volume II: Storm scale analysis. NOAA Tech. Memo. ERL ESG-15, 240 pp. [Available online at http://docs.lib.noaa.gov/noaa_documents /OAR/ERL_ESG/TM_ERL_ESG_15.pdf.]

Gensini, V. A., and T. L. Mote, 2015: Downscaled estimates of late 21 st century severe weather from CCSM3. Climatic Change, 129, 307-321, doi:10.1007/ s10584-014-1320-z.

Glickman, T., Ed., 2000: Glossary of Meteorology. 2nd ed. Amer. Meteor. Soc., 855 pp. [Available online at glossary.ametsoc.org/.]

Grice, H. P., 1975: Logic and conversation. Syntax and Semantics III-Speech Acts, P. Cole and J. L. Morgan, Eds., Academic Press, 41-58.

Guillot, E. M., T. M. Smith, V. Lakshmanan, K. L. Elmore, D. W. Burgess, and G. J. Stumpf, 2008: Tornado and severe thunderstorm warning forecast skill and its relationship to storm type. Preprints, 24th Int. Conf. on Interactive Information Processing Systems for Meteorology, Oceanography, and Hydrology, New Orleans, LA, Amer. Meteor. Soc., 4A.3. [Available online at https://ams.confex.com/ams/88Annual /techprogram/paper_132244.htm.]

Harrison, M. R., 1982: The media and public perceptions of climatic change. Bull. Amer. Meteor. Soc., 63, 730-730, doi:10.1175/1520-0477(1982)063<0730:TM $\mathrm{APPO}>2.0 . \mathrm{CO} ; 2$.

Holsti, O. R., 1969: Content Analysis for the Social Sciences and Humanities. Addison-Wesley, 235 pp.

Huschke, R. E., Ed., 1959: Glossary of Meteorology. 1st ed. Amer. Meteor. Soc., 638 pp.

Kingsmill, D. E., and R. M. Wakimoto, 1991: Kinematic, dynamic, and thermodynamic analysis of a weakly sheared severe thunderstorm over northern Alabama. Mon. Wea. Rev., 119, 262-297, doi:10.1175/15200493(1991)119<0262:KDATAO>2.0.CO;2.

Krippendorff, K., 2012: Content Analysis: An Introduction to Its Methodology. Sage, $456 \mathrm{pp}$.

Lehmann, C., 2005: Pleonasm and hypercharacterisation. Yearbook of Morphology 2005, G. Booij and J. Van Marle, Eds., Springer, 119-154.

McKenny, A. F., J. C. Short, and S. M. Newman, 2012: CAT scanner-Computer-aided text analysis tool. Version 1.0. [Available online at www.amckenny .com/CATScanner/.]

Miller, D., and A. Petrolito, 2008: Anticipating pulse severe thunderstorms using the WSR-88D all-tilts display. National Weather Service Eastern Region Tech. Attachment 2008-02, 11 pp. [Available online at http://docs.lib.noaa.gov/noaa_documents/NWS /NWS_ER/Eastern_Region_Tech_Attachment /TA_2008-02.pdf.]

NTSB, 1986: Aircraft accident report: Delta Air Lines Inc., Lockheed L-1011-385-1, N726DA, Dallas/Fort Worth - International Airport, Texas, August 2, 1985. NTSB/AAR-86/05, 164 pp. [Available online at www .ntsb.gov/investigations/AccidentReports/Reports /AAR8605.pdf.]

NWS, 2016: National Weather Service Glossary. [Available online at w1.weather.gov/glossary/.]

Rose, L. S., J. A. Stallins, and M. L. Bentley, 2008: Concurrent cloud-to-ground lightning and precipitation enhancement in the Atlanta, Georgia (United States), urban region. Earth Interact., 12, doi:10.1175/2008EI265.1.

Schultz, D., 2013: Eloquent Science: A Practical Guide to Becoming a Better Writer, Speaker, and Atmospheric Scientist. Amer. Meteor. Soc., 412 pp.

Short, J. C., J. C. Broberg, C. C. Cogliser, and K. C. Brigham, 2009: Construct validation using computeraided text analysis (CATA): An illustration using entrepreneurial orientation. Organ. Res. Methods, 13, 320-347, doi:10.1177/1094428109335949.

SPC, 2015: SPC products. NOAA/NWS/Storm Prediction Center. [Available online at www.spc.noaa.gov /misc/about.html.]

Stewart, A. E., C. A. Williams, M. D. Phan, A. L. Horst, E. D. Knox, and J. A. Knox, 2016: Through the eyes of the experts: Meteorologists' perceptions of the probability of precipitation. Wea. Forecasting, 31, 5-17, doi:10.1175/WAF-D-15-0058.1.

Wakimoto, R. M., and V. Bringi, 1988: Dual-polarization observations of microbursts associated with intense convection: The 20 July storm during the MIST project. Mon. Wea. Rev., 116, 1521-1539, doi:10.1175/1520-0493(1988)116<1521:DPOOMA $>2.0 . \mathrm{CO} ; 2$.

Weisman, M. L., and J. B. Klemp, 1982: The dependence of numerically simulated convective storms on vertical wind shear and buoyancy. Mon. Wea. Rev., 110, 504-520, doi:10.1175/1520-0493(1982)110<0504:TD ONSC>2.0.CO;2.

Wilk, K. E., L. R. Lemon, and D. W. Burgess, 1979: Interpretation of radar echoes from severe thunderstorms: A series of illustrations with extended captions. Prepared for training of FAA ARTCC Coordinators, National Severe Storms Laboratory, 55 pp. 


\section{Science at Your Fingertips}

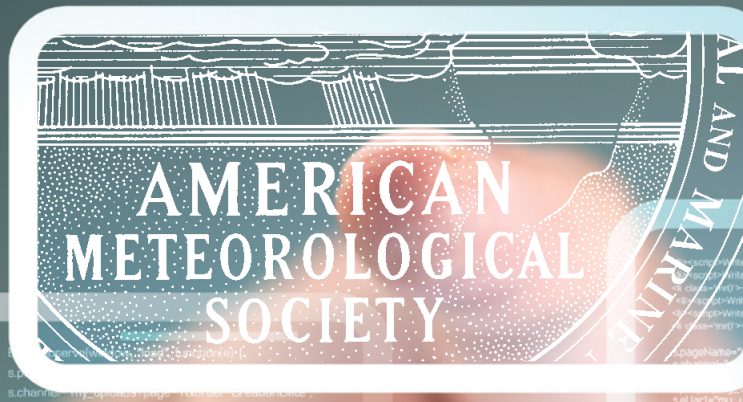

\section{AMS Journals are}

now optimized for viewing on your mobile device.

Access journal articles, monograph titles, and BAMS content using your iOS, Android, or Blackberry phone, or tablet.

Features include:

- Saving articles for offline reading

- Sharing of article links via email and social networks

- Searching across journals, authors, and keywords

And much more...

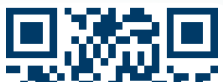
gror 마. 直社
Scan code to connect to journals.ametsoc.org
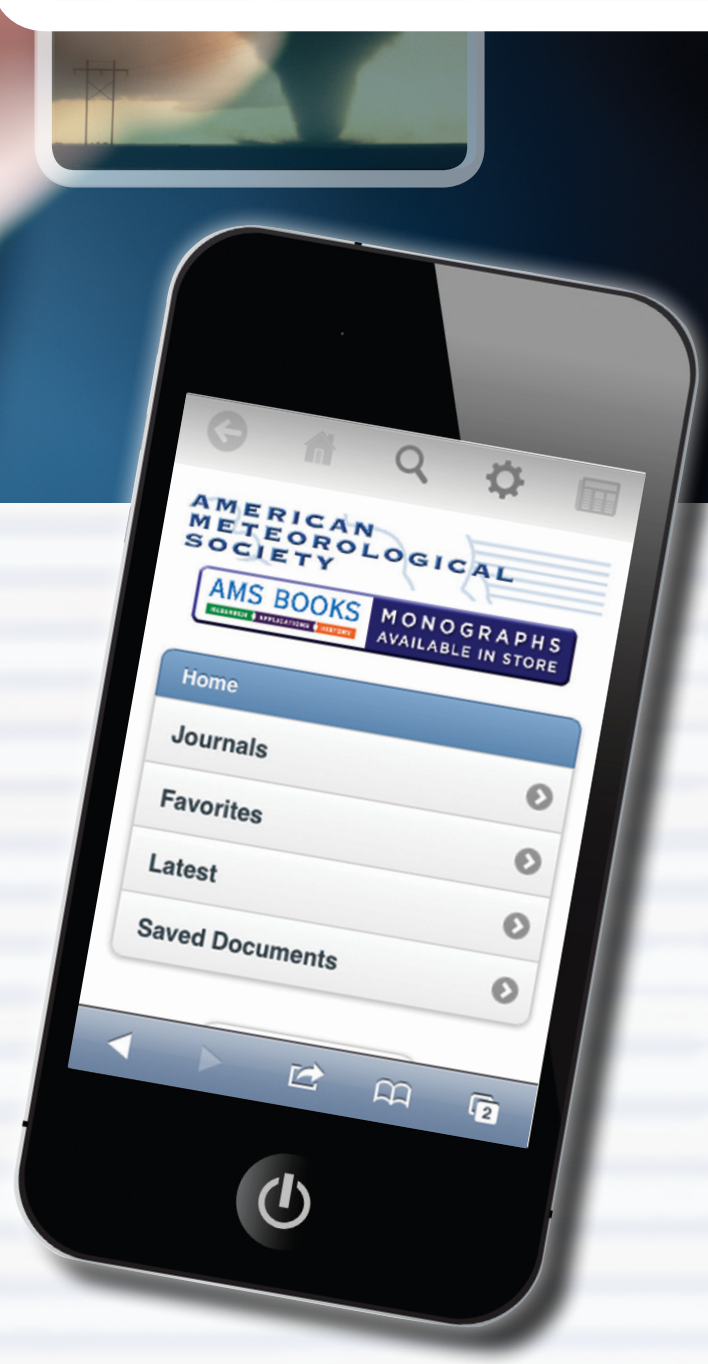

A MERICAN METEOROLOGICAL SOCIETY 